\title{
NERVE FIBER GROWTH IN CULTURE ON FIBRONECTIN, COLLAGEN, AND GLYCOSAMINOGLYCAN SUBSTRATES ${ }^{1}$
}

\author{
SALVATORE CARBONETTO, ${ }^{* 2}$ MICHAEL M. GRUVER, ${ }^{*}$ AND DAVID C. TURNER \\ Departments of * Pharmacology and Biochemistry, State University of New York Upstate Medical Center, \\ Syracuse, New York 13210
}

Received November 4, 1982; Revised May 31, 1983; Accepted June 6, 1983

\begin{abstract}
In an initial report (Carbonetto, S. T., M. M. Gruver, and D. C. Turner (1982) Science 216: 897899) we described the use of 2-hydroxyethylmethacrylate (HEMA) in preparing defined culture substrates for studying nerve fiber growth. In those studies fibronectin and collagen were conspicuous, among a variety of HEMA-embedded proteins, in supporting fiber growth of embryonic neurons from chick dorsal root ganglia. Here we further document and extend our preliminary studies, especially with regard to the interaction of growing nerve fibers with fibronectin. HEMA substrates were prepared with proteolytic fragments of fibronectin, each of which had one or more of the functional sites of the intact molecule. Only those fragments of fibronectin that retained the region of the molecule known to mediate myoblast attachment were active in supporting nerve fiber growth. When added in excess to the culture medium, the smallest of the active fragments inhibited fiber growth on substrates that contained intact fibronectin. In culture medium depleted of serum fibronectin, HEMA gels containing collagens purified from connective tissues (types I and III) or from basement membranes (type IV) were about as effective as HEMA substrates containing fibronectin in supporting fiber growth. Nerve fiber growth on collagen substrates proceeded in the absence of fibronectin in the culture medium. Several glycosaminoglycans (heparin, chondroitin sulfate, hyaluronic acid) were ineffective as substrates for fiber growth. Treatment of HEMA/ fibronectin gels with heparin or incorporation of heparin along with fibronectin in the gel profoundly diminished the efficacy of fibronectin in supporting nerve fiber growth. Our studies suggest that the growth of nerve fibers on fibronectin substrates results from direct interaction with a specific portion of the fibronectin molecule and that this interaction can be inhibited by heparin and possibly other glycosaminoglycans.
\end{abstract}

Several recent experiments have implicated the extracellular matrix of the nervous system in control of nerve fiber growth, neuronal differentiation, and neuroblast migration. Among the most notable are those of McMahan and his colleagues (Marshall et al., 1977; McMahan et al., 1978; Sanes et al., 1978). They showed that muscle cell "ghosts," consisting of the basal lamina left behind by degenerated skeletal muscle, signaled regenerating nerve fibers to stop growing and form nerve terminals.

The molecular composition of the extracellular matrix

\footnotetext{
${ }^{1}$ This work was supported by grants to S. C. from the National Science Foundation (Grant BNS 80-21860) and the Amyotrophic Lateral Sclerosis Society of America, and by grants to D. C. T. from the National Institutes of Health (Grant HD 17060) and the Muscular Dystrophy Association. We thank J. DeGeorge for helpful discussions and J. Robson for suggesting improvements in the manuscript.

${ }^{2}$ To whom correspondence should be addressed, at the Department of Pharmacology, SUNY Upstate Medical Center, Syracuse, NY 13210.
}

of neurons is still being described for peripheral and central nervous systems as well as for the relatively simple case of neurons in culture. Known constituents include fibronectin (Schachner et al., 1978; Kavinsky and Garber, 1979; Newgreen and Thiery, 1980; Hatten et al., 1982; Sanes, 1982), collagens (Peters et al., 1976; Bunge et al., 1980), laminin (Sanes, 1982), and glycosaminoglycans (Bondareff, 1967; Castejón, 1970; Toole, 1976; Margolis and Margolis, 1979; Gallagher et al., 1980). The differential distribution of these components in peripheral nerves and brain may be pivotal for the ability of nerve fibers to regenerate (Richardson et al., 1980). However, the nature of the interactions between neurons and components of the extracellular matrix and the effect of these interactions on the behavior of neurons during regeneration and development are largely a matter of speculation.

We have undertaken to evaluate the efficacy of several known components of the extracellular matrix in sup- 
porting nerve fiber growth by cultured neurons. To test these components individually, and in combinations which may reflect their association in vivo, we have incorporated them into hydrophilic gels of polymerized 2-hydroxyethylmethacrylate (HEMA). Such gels, in which the incorporated molecules are stably retained, can then be used as culture substrates, and they can be compared to gels prepared in the same fashion but containing no incorporated molecules (simple HEMA gels). In a preliminary report (Carbonetto et al., 1982) we showed that, on simple HEMA gels, cultured neurons attached but grew few nerve fibers. Fibronectin or collagen, among a variety of proteins incorporated into the gels, rendered them excellent substrates for nerve growth.

In this report we have documented more fully several of the points made earlier. In addition, we present more detailed studies of the molecular interactions between growing nerve fibers and fibronectin and of the effects of glycosaminoglycans (GAGs) on the growth of nerve fibers. Fragments of fibronectin produced by limited proteolysis were tested for their ability to promote nerve fiber growth. The only effective fragments were those known to mediate myoblast attachment (Ehrismann et al., 1982). It appears that a small region of the $M_{r}=$ 220,000 fibronectin subunit interacts directly with the surface of the growing nerve fiber. Furthermore, we show that the GAGs heparin, hyaluronic acid, and chondroitin sulfate alone do not support nerve fiber growth. When GAGs are incorporated along with fibronectin in HEMA gels or used in solution to treat HEMA/fibronectin gels, the efficacy of fibronectin as a substrate for fiber growth is greatly reduced.

\section{Materials and Methods}

Preparation of HEMA gel substrates. When polymerized, HEMA forms a clear hydrophilic gel. The methods for preparing HEMA gel substrates have been published (Civerchia-Perez et al., 1980; Carbonetto et al., 1982). Briefly, a solution of the molecule or molecules to be incorporated into the gel is added to a mixture of HEMA, ethylene glycol, sodium metabisulfite, and ammonium persulfate. This mixture is allowed to polymerize between two large microscope slides, and the gels are washed exhaustively in Tris-buffered saline (TBS), cut into conveniently sized circles, and placed in sterile Petri dishes ( $35 \mathrm{~mm}$ in diameter). For short-term cultures (24 to $48 \mathrm{hr}$ ), ultraviolet irradiation of the gel substrates for $1 \mathrm{hr}$ sufficiently reduced the incidence of contamination of the cultures. For longer-term cultures treatment of gels with gentamicin sulfate $(400 \mu \mathrm{g} / \mathrm{ml})$ for several hours was helpful. Once sterilized, the substrates were equilibrated for $1 \mathrm{hr}$ with medium in a $\mathrm{CO}_{2}$ incubator before use.

Characterization of modified HEMA gels. When polymerized, HEMA forms a hydrophilic gel with a pore size estimated between 4 and $40 \AA$ (Brock, 1973; Migliaresi et al., 1981). Consistent with this estimated pore size, HEMA gels used as a medium for gel electrophoresis excluded molecules as small as bromphenol blue $\left(M_{r}=\right.$ 670).

Modified HEMA gels were prepared by adding soluble molecules to the HFMA prior to polymerization of the gel. With a variety of radioiodinated proteins and peptides we have found that approximately $80 \%$ of the radioactivity added to HEMA remained associated with the gel. Approximately $20 \%$ of the radioactivity, along with a small amount of unpolymerized HEMA, remained on the glass microscope slides used as a polymerization chamber for the gel.

HEMA gels that had been polymerized in the presence of radiolabeled proteins or peptides were subjected to prolonged washing to assess the extent of incorporation and the rate of release of extraneous molecules from the gels (Fig. 1). Of the radiolabel originally added, 20 to $70 \%$ was removed in the first few washes, usually within $1 \mathrm{hr}$, whereas the residual radioactivity remained in the gel for days (Fig. 1, top). This variability in retention, although greater than that found in our preliminary studies (Carbonetto et al., 1982), is considerably less than that observed with other methods of preparing culture substrates (Turley and Roth, 1979). There was no consistent correlation between extent of release from IIEMA gels and the molecular weight of the species of molecule incorporated. For example, the small protein $\alpha$-bungarotoxin $\left(M_{r}=8000\right)$ was retained to a lesser extent than thyroxine $\left(M_{r}=777\right)$ (Fig. 1, top) and no more effectively than simple sugars such as mannose or glucosamine (Fig. 1, bottom). It should be noted that the variability with which a particular molecule was retained in the gels was usually less than $10 \%$ among separate preparations. Furthermore, addition of ${ }^{125} \mathrm{I}$-gelatin or $\left[{ }^{125} \mathrm{I}\right] \beta$-NGF (the $\beta$-subunit of nerve growth factor (NGF)) into HEMA gels was unaffected by adding unlabeled collagen or $\beta-\mathrm{NGF}$ in amounts up to $1 \mathrm{mg} / \mathrm{ml}$. Similarly, GAGs did not alter the amount of association of ${ }^{125}$ I-gelatin with HEMA gels (S. Carbonetto, unpublished observations).

Some fraction of soluble molecules in HEMA gels is apparently trapped at the surface of the gel and is accessible to the cells (Civerchia-Perez et al., 1980; Carbonetto et al., 1982). To get a rough estimate of the fraction of molecules at the surface, gels containing ${ }^{125} \mathrm{I}$-gelatin were treated with a proteolytic enzyme (trypsin, $M_{r}=24,000$ ) that presumably cannot penetrate the gel. Trypsin released 14 to $19 \%$ of the radioactivity that had been retained in the gel for 6 days (Fig. 1, top), from which we estimate that about a fifth of the trapped gelatin polypeptide is exposed at the surface of the gel.

Cell culture. Cultures of dorsal root ganglia (DRG) from 9- to 10-day chick embryos were prepared by methods described previously (Carbonetto and Stach, 1982). Cells were routinely seeded onto culture substrates at low density of about $5 \times 10^{5}$ cells/ml of growth medium. The growth medium ${ }^{3}$ consisted of: Eagle's minimum essential medium (Grand Island Biological Co.), $10 \%$ fibronectin-depleted horse serum (see below), $\beta$-NGF $\left(3.8 \times 10^{-11} \mathrm{M}\right)$, cytosine arabinoside $\left(10^{-6} \mathrm{M}\right)$, and gen-

\footnotetext{
${ }^{3}$ A recent paper by Bunge et al. (1982) described a defined growth medium for DRGs from rat embryos. In preliminary experiments we have found that this medium also supports growth of nerve fibers from chick embryo DRG neurons cultured on HEMA/collagen or HEMA/ fibronectin substrates. It will be the growth medium of choice in future studies.
} 

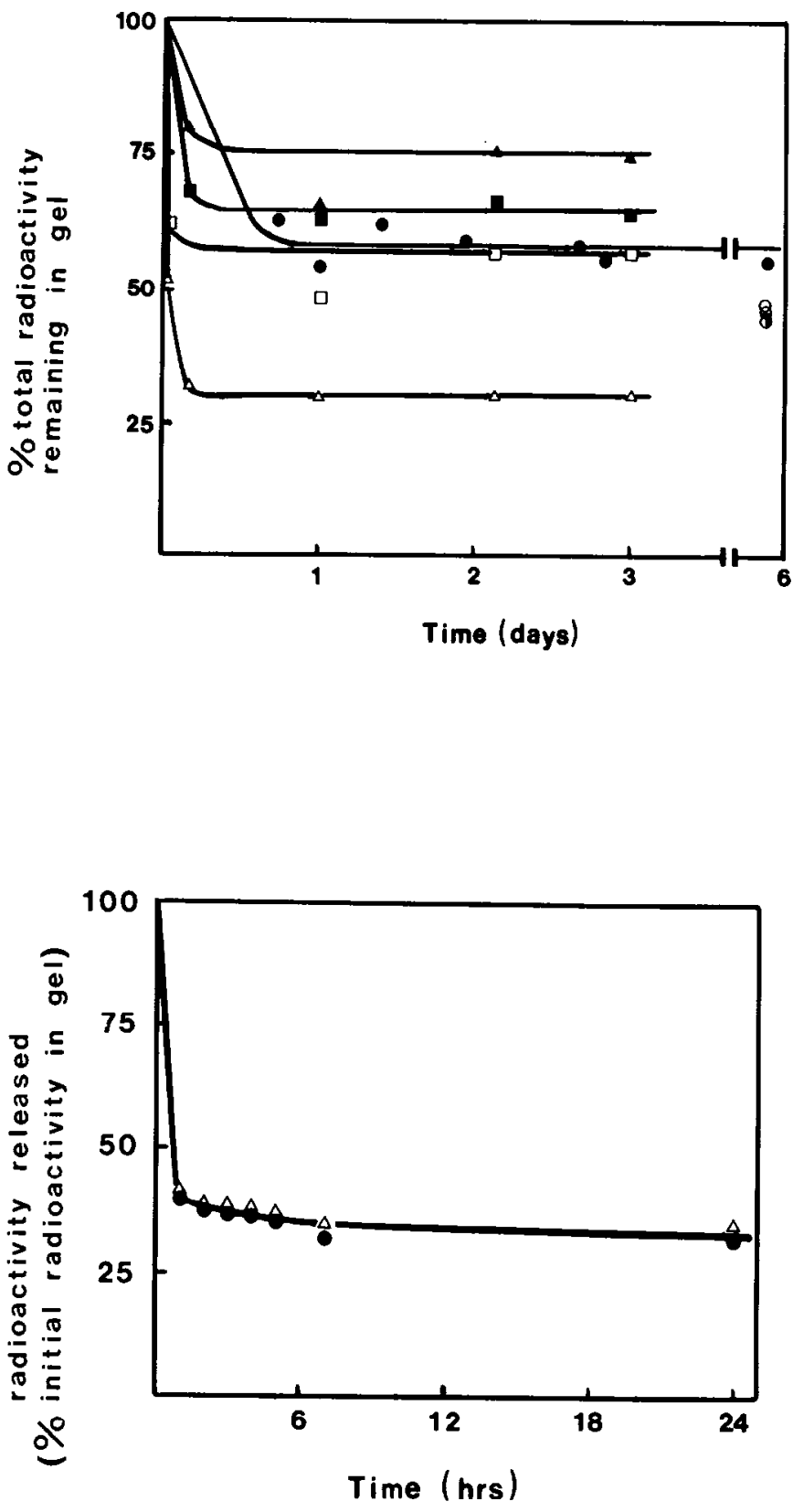

Figure 1. Top, Washout of radiolabeled compounds from HEMA gels. The following ${ }^{125}$-labeled compounds in TBS were added prior to polymerization of the HEMA gels: thyroxine $(\boldsymbol{\Delta}-\mathbf{\Delta}), \beta$-NGF ( $-\mathbf{\square})$, insulin $(\square-\square)$, gelatin (-O), and $\alpha$-bungarotoxin $(\Delta-\Delta)$. The polymerized gel was cut into disks of approximately $10 \mathrm{~mm}$ diameter, placed into test tubes, and counted. The gels were then placed in a $37^{\circ} \mathrm{C}$ incubator in $2 \mathrm{ml}$ of TBS. At various times, two or three identical gels were removed from the incubator, the TBS was removed, and gels were washed two times with an additional $0.5 \mathrm{ml}$ each of TBS. The gels and pooled TBS washes were then counted separately. The radioactivity remaining in the gel is expressed as a per centage of the amount initially present. In one series of experiments, HEMA gels containing radiolabeled gelatin were maintained at $37^{\circ} \mathrm{C}$ for 6 days, resulting in the loss of approximately $55 \%$ of the initial radioactivity. The gels were then washed as above and placed in $0.025 \%$ trypsin in TBS at $37^{\circ} \mathrm{C}$ for an additional $30(\mathrm{O}), 60(\Theta)$, or $90(\Theta) \mathrm{min}$. This resulted in the loss of about $10 \%$ of the radioactivity originally present (or approximately $20 \%$ of the radioactivity remaining in the gel after 6 days). Bottom, Washout of $\left[{ }^{3} \mathrm{H}\right]$ mannose or $\left[{ }^{3} \mathrm{H}\right]$ glucos- tamicin sulfate $(40 \mu \mathrm{g} / \mathrm{ml}$; Schering Corp. Cultures were maintained at $37^{\circ} \mathrm{C}$ in a humidified incubator equilibrated with $5 \% \mathrm{CO}_{2} / 95 \%$ air.

DRG cells were seeded directly onto HEMA gel substrates in a small volume ( 75 to $100 \mu \mathrm{l}$ ) of growth medium and were permitted to attach for 3 to $4 \mathrm{hr}$ in the incubator. Then an additional $1.5 \mathrm{ml}$ of growth medium was added and the cultures were returned to the incubator for 1 to 2 days.

PC12 cells were a gift from Dr. D. Ishii, Columbia University, and were derived from a pheochromocytoma cell line established by Dr. L. Greene, New York University School of Medicine. PC12 cells were maintained as described by Greene and Tischler (1976).

Measurements of cell attachment. A suspension of DRG cells in growth medium was seeded onto HEMA gels, taking care to distribute the cells evenly across the substrate. After $2 \mathrm{hr}$ in the incubator the cultures were removed, washed gently with medium to remove any unattached cells, and scored systematically (see below) with an inverted phase contrast microscope. Attached neurons and non-neuronal cells were scored separately within each of five visual fields scanned per culture. The two classes of cells were readily distinguishable; many of the non-neuronal cells were partially or completely spread after $2 \mathrm{hr}$, whereas any unspread non-neuronal cells had an irregular shape unlike that of the smooth, spherical neurons.

Measurement of nerve fiber growth. The principal consideration in devising an assay for nerve fiber growth was to ensure that the neurons scored not be in contact with other cells. There were two reasons for this: (1) to allow identification of the cell of origin of nerve fibers and accurate determination of fiber length, and (2) to avoid complications which might result from contact of neurons with non-neuronal cells, which has been shown to stimulate fiber growth (Ludueña, 1973). Accordingly, we chose to seed DRG cells at a low density (see above).

Following an appropriate period of nerve fiber growth, the cultures were fixed with glutaraldehyde $(2.5 \%$ in 100 mM phosphate buffer, $\mathrm{pH}$ 7.2). Each culture was scanned in the light microscope for neurons not in contact with other cells, and the percentage of those neurons which had extended nerve fibers was determined. The lengths of nerve fibers on each cell were measured with an eyepiece micrometer. From this an estimate of the total nerve fiber growth per 100 neurons was calculated by

amine from HEMA gels. The amount of the compounds re maining at various times could not be determined directly by scintillation counting of the gels. This was because incorporation of ${ }^{3} \mathrm{H}$-compounds into HEMA gels resulted in extensive quenching. Instead, circular disks of HEMA gel containing $\left[{ }^{3} \mathrm{H}\right]$ mannose $(\Delta-\Delta)$ or $\left[{ }^{3} \mathrm{H}\right]$ glucosamine $(-)$ were cut and placed in $5 \mathrm{ml}$ of TBS. At regular intervals the TBS was removed, a $0.5-\mathrm{ml}$ aliquot was transferred to a scintillation vial, and $5 \mathrm{ml}$ of fresh TBS were added to each gel. The amount of radioactivity initially in the gel was calculated from the amount added to the polymerization mixture, the volume of the polymerization mixture, and the volume of each disk. The radioactivity which appeared in the TBS is expressed as a percentage of the amount estimated to have originally been incorporated into the gels. 

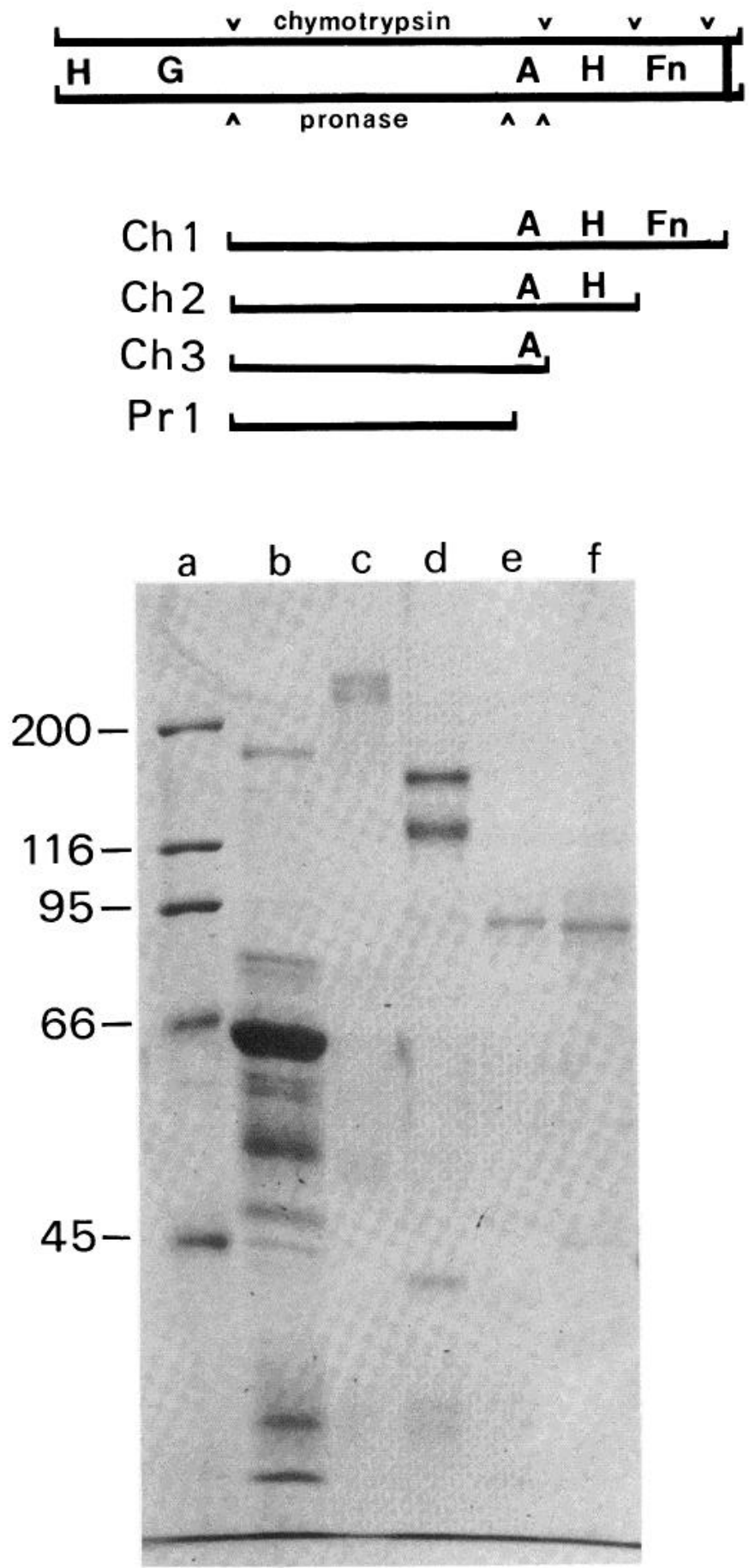

Figure 2. Top, Description of the possible arrangement of functional domains within horse serum fibronectin and the derivation, by limited digestion with chymotrypsin and pronase, of fragments containing those domains (modified from Ehrismann et al., 1982). The four proteolytic fragments (Ch 1, Ch 2 , $\mathrm{Ch} 3$, and $\operatorname{Pr} 1$ ) were generated as described under "Materials and Methods." The functional domains within the fragments are designated as follows: $H$, heparin-binding sites; $G$, gelatinbinding site; $A$, cell attachment site; $F n$, site of fibronectin selfassociation. Also shown (arrowheads) are the sites of proteolytic cleavage of fibronectin by chymotrypsin and pronase. The vertical line to the right indicates the location of disulfide bonds linking two subunits of native fibronectin. Bottom, Electrophoretic analysis of fibronectin and related reagents used in nerve fiber growth experiments. Reduced samples of proteins were multiplying the percentage of neurons that had grown fibers by the mean of the total nerve fiber length per cell. In some cases (Fig. 5) the amount of fiber growth was low because a relatively small percentage of neurons had extended fibers early on. The measured nerve fibers were always at least $10 \mu \mathrm{m}$ in length and sometimes extended for several hundred micrometers. Cells were permitted to grow for various times from 24 to $48 \mathrm{hr}$, again with the aim of obtaining a reasonable sampling of neurons that had extended fibers but had not contacted other cells. Variability in the growth rate in separate trials of the same experimental design could be offset somewhat by expressing nerve fiber growth as a percentage of growth on control (simple) HEMA gels. In most cases we have reported the percentage of growing neurons as well as the average of the total nerve fiber growth per neuron so that the absolute amount of fiber growth can be calculated (e.g., Fig. 7). Fibers on 30 to 60 neurons were measured for a sample within any experiment, and most experiments were repeated three times.

Fibronectin and fibronectin fragments. Affinity chromatography of horse serum (Grand Island Biological Co.) on gelatin coupled to Sepharose 4B (Pharmacia) yields fibronectin-depleted horse serum (Fig. 2, lane b; Chiquet et al., 1979). Fibronectin is eluted from the column with $4 \mathrm{M}$ urea (Fig. 2, lane c). Controlled chymotryptic digestion of native fibronectin (Fig. 2, top) bound to gelatinSepharose (Ehrismann et al., 1981) releases a mixture of fragments ( $\mathrm{Ch} 1, \mathrm{Ch} 2)$ which together contain the fibronectin-binding region, one of the heparin-binding regions, and the portion of the molecule which mediates myoblast attachment (Fig. 2, top). The molecular weights of these fragments were estimated by Ehrismann et al. (1982) to be 160,000 and 135,000, respectively (Fig. 2, lane d). Further treatment with chymotrypsin of material released from gelatin-Sepharose produces the $\mathrm{Ch} 3$ fragment (Fig. 2, lane $e$; originally estimated to be $M_{r}=$ 105,000; Ehrismann et al., 1982), which contains only the myoblast attachment site. Pronase treatment of native fibronectin or its chymotryptic fragments yields a subfragment of $\mathrm{Ch} 3(\operatorname{Pr} 1)$ which was originally estimated to have a $M_{r}=93,000$ (Fig. 2, lane $f$ ) and which lacks any known function (Ehrismann et al., 1982). In this report we refer to the various proteolytic fragments according to the proteases used in generating them and not by their molecular weights. This change from earlier work cited above was adopted because recent data utilizing two different SDS-PAGE systems (D. Turner, unpublished observations) have given conflicting molecular weight estimates for certain fragments and called into question our original estimates.

Other materials. Pure calf skin type I, human type III, and bovine renal glomerular basement membrane type

subjected to SDS-PAGE (Laemmli, 1970). Lane $a$, molecular weight standards: myosin $\left(M_{r}=200,000\right), \beta$-galactosidase $\left(M_{r}\right.$ $=116,000)$, phosphorylase B $\left(M_{r}=95,000\right)$, bovine serum albumin $\left(M_{r}=68,000\right)$, and ovalbumin $\left(M_{r}=45,000\right)$; lane $b$, horse serum depleted of fibronectin; lane $c$, horse serum fibronectin; lane $d$, mixture of $\mathrm{Ch} 1$ and $\mathrm{Ch} 2$ fragments; lane $e, \mathrm{Ch}$ 3 fragment, produced by prolonged chymotryptic digestion of fragments in lane d; lane $f, \operatorname{Pr} 1$ fragment. 
IV collagens were a gift from Dr. J. William Freytag, E. I. DuPont de Nemours \& Co. Bovine achilles tendon collagen was purchased (Sigma Chemical Co., type V). All collagens were dissolved in $50 \mathrm{~mm}$ acetic acid and then dialyzed exhaustively against TBS before use. Sources of other reagents were: cytochrome $c$, heparin, chondroitin sulfate, hyaluronic acid, and wheat germ agglutinin, from Sigma; polylysine and polyornithine from Miles-Yeda; $\beta$-NGF and $\left[{ }^{125} \mathrm{I}\right] \beta-\mathrm{NGF}$, a generous gift from Dr. R. W. Stach, State University of New York Upstate Medical Center. All other radioactively labeled compounds were purchased from New England Nuclear.

\section{Results}

Behavior of cells on HEMA gel substrates. Fibroblastic cells are able to attach to a wide variety of culture substrates. This initial attachment can occur at low temperature or after aldehyde fixation of cells. The molecular requirements for initial attachment of cells in culture appear to be rather nonspecific, and this process may be unphysiological (see Grinnell, 1978, for review). Whatever the mechanism of initial attachment, fibroblasts attain their normal, well spread shape only on substrates coated with adhesive proteins, most notably fibronectin. Confirming this generally observed behavior, the non-neuronal cells (fibroblasts and glia) in our cultures attach in equal numbers to simple HEMA gels or modified HEMA gels (Table I, Fig. 3A) but spread well only on HEMA/fibronectin and HEMA/collagen substrates (Fig. $3 B$ ). Interestingly, neurons also fit this pattern: attaching equally well to simple HEMA, HEMA/fibronectin, or HEMA/collagen (Table I), but attaining their characteristically differentiated shape of spherical cell bodies with long processes only on modified HEMA gels (Carbonetto et al., 1982; Fig. 3). Presumably, initial attachment of neurons is relatively nonspecific, whereas subsequent fiber outgrowth depends on more specific molecular interactions.

Since neurons which attach to non-neuronal cells grow nerve fibers at a faster rate than those attached to the culture substrate (Ludueña, 1973), the spreading of nonneuronal cells might contribute to the difference in fiber growth which we see on simple and modified HEMA gel substrates. Aware of this problem, we have kept the number of cells in our primary cultures low so that our

\section{TABLE I}

Cell attachment to HEMA gel substrates

Cells were assayed for attachment to HEMA substrates as described under "Materials and Methods." The number of attached cells within microscopic fields ( 5 per gel) were counted on the five replicate HEMA substrates within each group. The total number of cells counted on each substrate and the number of neurons counted are shown with their respective standard errors. The number of non-neuronal cells was calculated by subtracting the number of neurons from the total number of cells counted on each substrate.

\begin{tabular}{lccc}
\hline \multicolumn{1}{c}{ Substrate } & $\begin{array}{c}\text { No. of Cells/ } \\
\text { Culture }\end{array}$ & $\begin{array}{c}\text { No. of Neu- } \\
\text { rons/Culture }\end{array}$ & $\begin{array}{c}\text { No. of Non- } \\
\text { neuronal } \\
\text { Cells/Culture }\end{array}$ \\
\hline HEMA & $172 \pm 5.7$ & $65 \pm 2.7$ & 100 \\
HEMA/Collagen & $154 \pm 5.8$ & $70 \pm 3.2$ & 84 \\
HEMA/Fibronectin & $164 \pm 5.4$ & $71 \pm 3.3$ & 93 \\
\hline
\end{tabular}

analysis of nerve fiber growth can be restricted to neurons not in contact with other cells (see "Materials and Methods"). This eliminated effects resulting from contact of neurons with non-neuronal cells but not other more indirect effects. For example, as a result of their differing interactions with various substrates, production and/or release of soluble trophic agents by non-neuronal cells (Varon and Bunge, 1978) might be altered. In an earlier attempt to address this issue, we showed that removal of greater than $90 \%$ of the non-neuronal cells had no effect on the growth of nerve fibers on simple or modified HEMA gels (Carbonetto et al., 1982). However, the effects, if any, of the remaining $10 \%$ of the nonneuronal cells on fiber growth were unknown. To reexamine this point, we have used a cloned cell line, $\mathrm{PC} 12$, the cells of which are derived from an adrenal tumor but develop many neuronal properties when exposed to NGF (Greene and Shooter, 1980). We have cultured PC12 cells on simple HEMA gels as well as HEMA/collagen gels. Despite the absence of any cells of another type, PC12 cells supplied with NGF grew long processes on HEMA/collagen gels, yet showed little growth on simple HEMA gels (Fig. 3). This result supports our earlier conclusion that the growth of nerve fibers on modified HEMA gels does not result from differences in the behavior or metabolism of non-neuronal cells. Furthermore, that PC12 cells exposed to the same NGF-containing medium grow fibers when attached to HEMA/collagen gels, but not on simple HEMA gels, confirms the necessity of a properly adhesive matrix for nerve fiber growth.

Nerve fiber growth on fibronectin, collagens, and GAGs. The contribution of individual constituents of the extracellular matrix to nerve fiber growth is difficult to assess in vivo. With defined HEMA substrates we sought to compare the ability of different molecules known to reside in the extracellular matrix of the nervous system to support the growth of nerve fibers.

Collagen types I and III are derived from connective tissue and have similar distributions in the body. When incorporated into HEMA gels, these two types of collagen were about equally effective in supporting nerve fiber growth (Fig. 4). Yet another type of collagen, type IV, isolated from basement membranes rather than from the interstitium, also proved a good substrate for fiber growth. For a variety of cell types the efficacy of collagen as a substrate results from its ability to collect fibronectin. However, nerve fiber growth on all three types of collagen which we tested was unaffected whether whole or fibronectin-depleted horse serum was used in the culture medium (S. Carbonetto, unpublished observations) and compared favorably with fiber growth on HEMA/fibronectin substrates (Fig. 4).

Variable retention of molecules within HEMA gels (Fig. 1) makes small differences in nerve fiber growth on modified HEMA gels an unreliable indicator of the efficacy of a particular molecule in supporting fiber growth. However, when fiber growth on HEMA/GAG substrates is compared with that on HEMA/fibronectin or HEMA/ collagen substrates, the difference is striking. Unlike fibronectin and collagens, the three GAGs chondroitin sulfate, heparin, and hyaluronic acid supported virtually 
The Journal of Neuroscience Nerve Growth on Fibronectin, Collagen, and Glycosaminoglycans
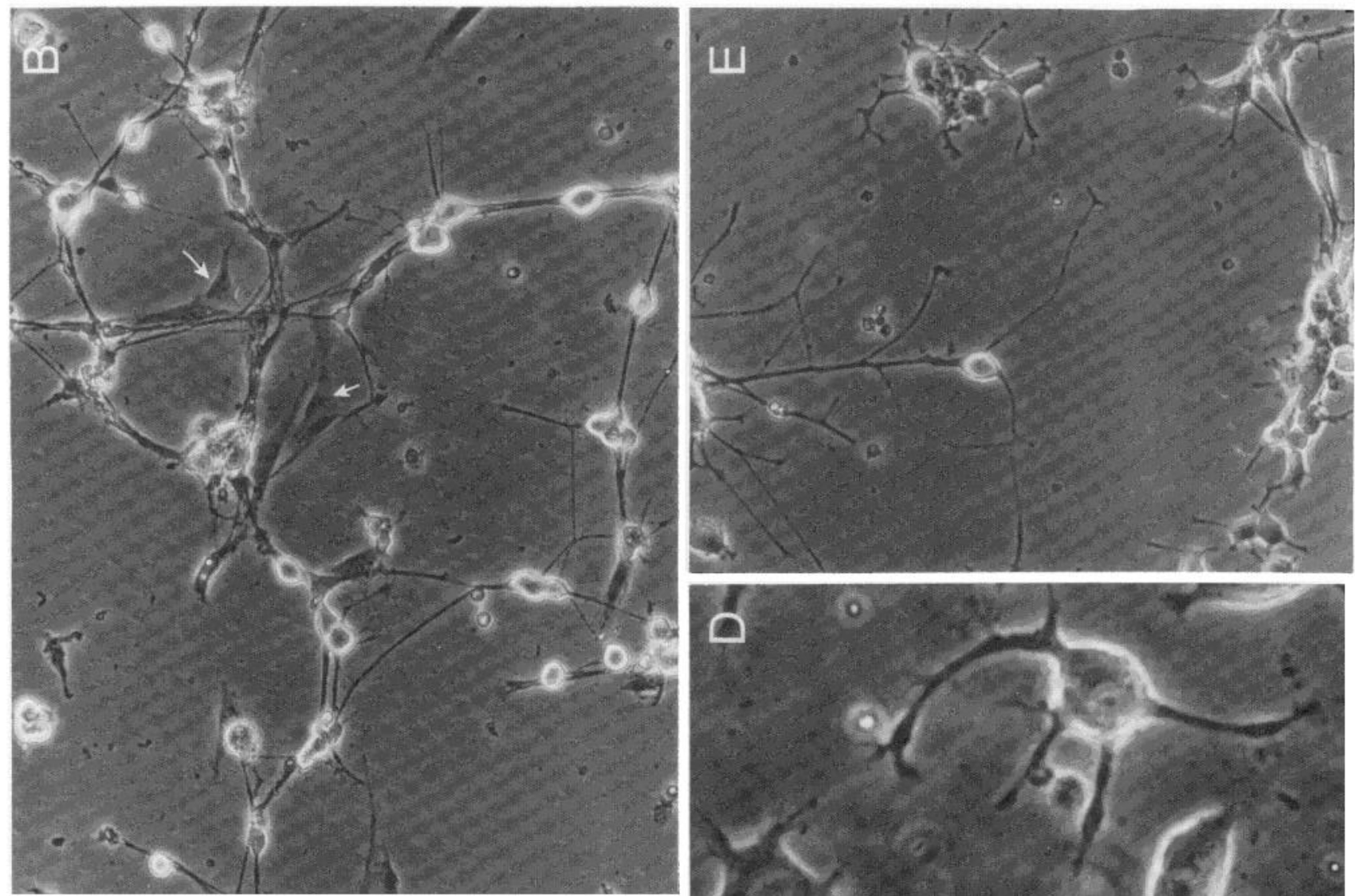

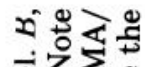

就空

【步项

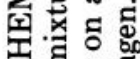

으를

엉요

ह

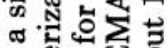

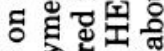

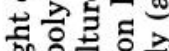

말흘 궁

ㄹ. 렁요

동 형

D

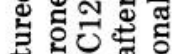

可远的

๑ั

焉怘先

บ

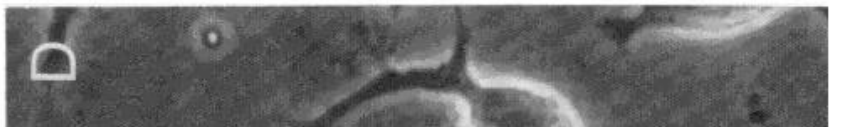

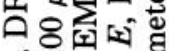

বㄷ⼯ㅁ

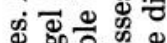

击

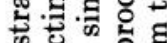

象

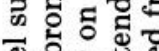

政造击

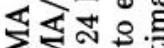

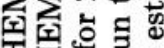

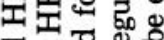

\%

돌

항

다의

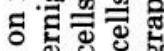

.

일료

以

豞宁运

\& 3.

글ำำํำ

눙형

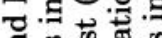

สี

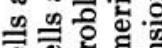

ฮె छ

才ुप

둥

․원.

능 응 뒁

吅

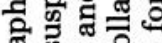

냉

응

㟧

내

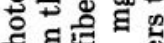

क

论

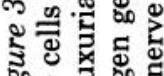

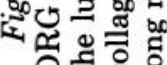




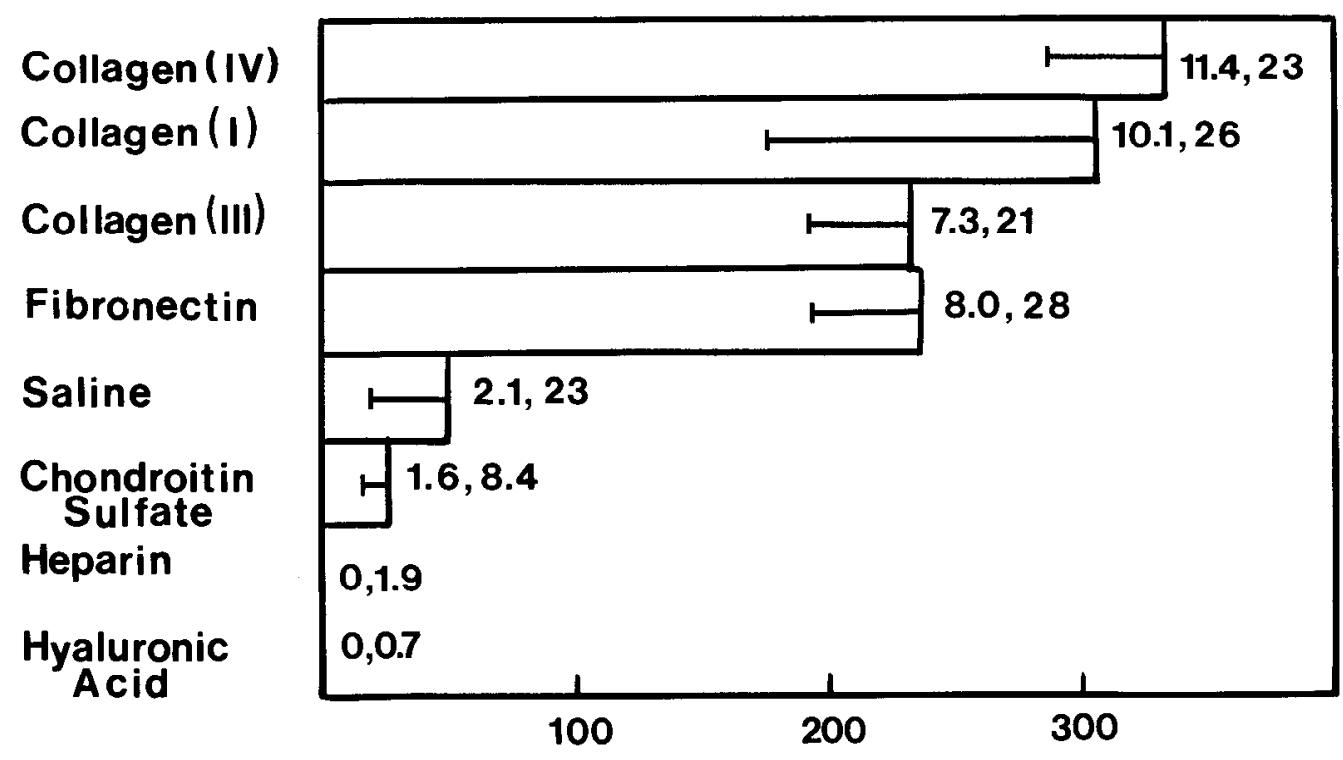

\section{Nerve Fiber Length $(\mu \mathrm{m} / 100$ cells $)$}

Figure 4. Nerve fiber growth on HEMA gels containing constituents of the extracellular matrix. A suspension of neurons in medium containing fibronectin-depleted horse serum was seeded onto HEMA gels polymerized with the following additions: collagen (types I, III, and IV at $1 \mathrm{mg} / \mathrm{ml}$ each), fibronectin $(1 \mathrm{mg} / \mathrm{ml})$, hyaluronic acid $(0.25 \mathrm{mg} / \mathrm{ml})$, heparin $(1 \mathrm{mg} / \mathrm{ml})$, and chondroitin sulfate $(1 \mathrm{mg} / \mathrm{ml})$. Cultures were fixed at $24 \mathrm{hr}$ for determination of nerve fiber growth. The first number to the right of each bar is the percentage of neurons within each visual field that extended nerve fibers; the second number is the number of neurons within each standard visual field. Data are expressed as the mean nerve fiber length per 100 cells, and the standard error of the mean is shown for each bar. The mean fiber length per 100 cells is calculated by multiplying the percentage of neurons that extended fibers by the nerve fiber length per cell (see "Materials and Methods").

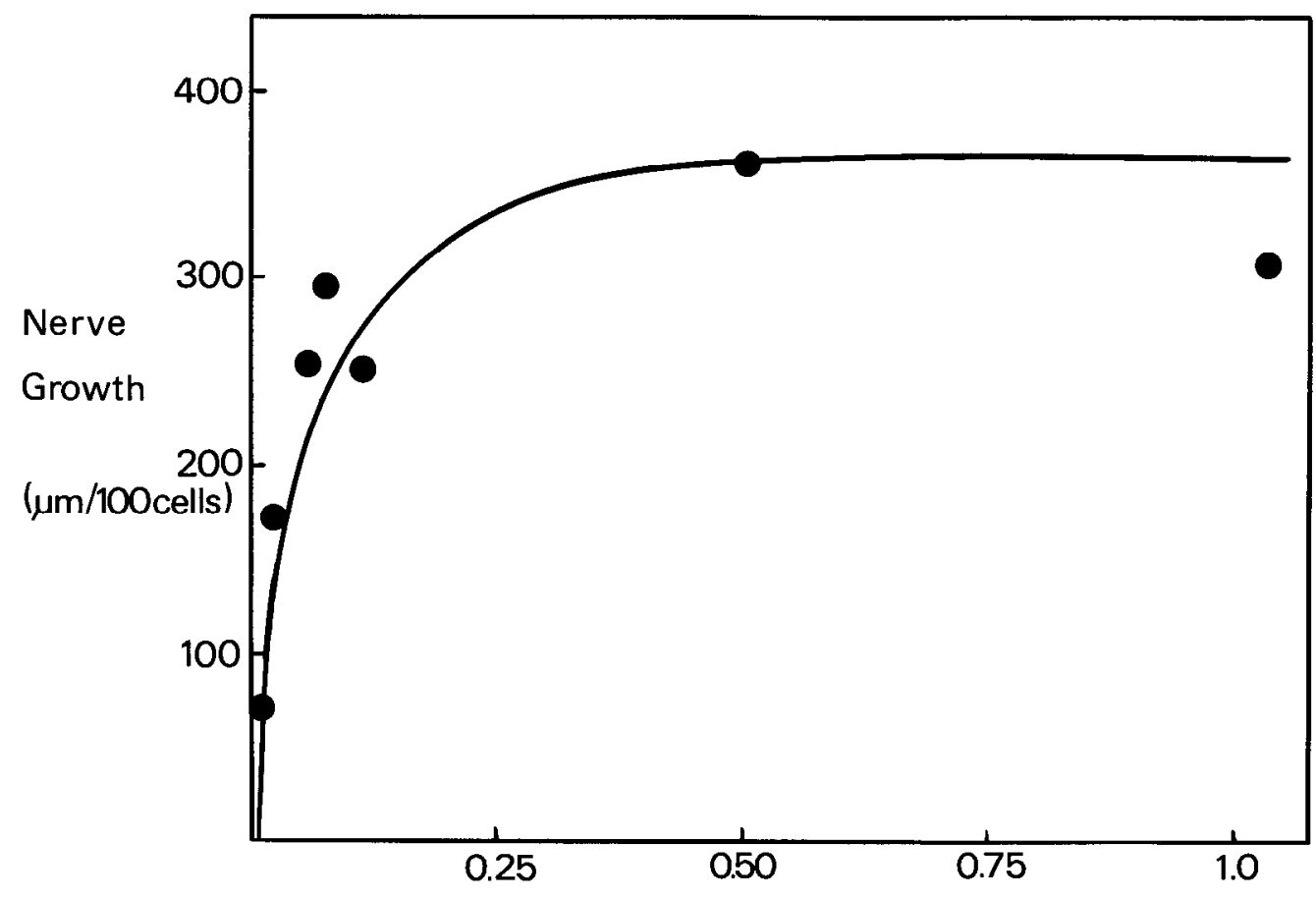

Fibronectin $(\mathrm{mg} / \mathrm{ml})$

Figure 5. Growth of nerve fibers on HEMA/fibronectin substrates. DRG cells were cultured overnight on HEMA gel substrates containing fibronectin. Nerve fiber growth was calculated from the mean nerve fiber length per cell and the percentage of cells growing nerve fibers (see "Materials and Methods"). The standard error is smaller than the solid circles. 
no nerve fiber growth, and growth on HEMA/GAG substrates was reduced below the small amount which occurs on simple HEMA gels (Fig. 4). Indeed, incorporation into HEMA of GAGs over a wide range of concentrations (heparin, 5 to $300 \mu \mathrm{g} / \mathrm{ml}$ (Table II) and hyaluronic acid or chondroitin sulfate, up to $1000 \mu \mathrm{g} / \mathrm{ml}$ (not shown)) inhibited attachment of neurons to HEMA, and those cells that did attach extended only a few short nerve fibers. In contrast, HEMA gels containing fibronectin (Fig. 5) or collagen (Fig. 6) exhibited a concentrationdependent increase in supporting fiber growth.

Nerve fiber growth on proteolytic fragments of fibronectin. Fibronectin is a functionally heterogeneous protein (for review see Akiyama et al., 1981). Several fragments produced by partial proteolytic digestion of native horse serum fibronectin have been shown to retain one or more functions of the intact molecule. Characterization of these fragments has made it possible to map five functional domains within the fibronectin molecule. We have incorporated into HEMA gels various proteolytic fragments of fibronectin which contain these various functional domains and compared the growth of nerve fibers on these proteolytic fragments with the growth on gels containing native fibronectin or on simple HEMA gels (Fig. 7).

A mixture of the $\mathrm{Ch} 1$ and $\mathrm{Ch} 2$ proteolytic fragments, which lack a gelatin-binding site but which together contain binding sites for heparin, a site that promotes myoblast attachment, and a fibronectin self-association site (see Fig. 2), supported nerve fiber growth comparable to that on HEMA gels with native fibronectin (Fig. 7). The Ch 3 fragment, which contains the site that mediates myoblast attachment but contains neither gelatin-bind- ing nor self-association sites (Fig. 2), was also almost as effective as native fibronectin in supporting fiber growth (Fig. 7). In contrast, the $\operatorname{Pr} 1$ fragment, which can be derived from the Ch 3 fragment and which lacks the myoblast attachment site as well as any other known functional domains (Fig. 2), supported little nerve fiber growth (Fig. 7).

Because our experiments with HEMA substrates containing proteolytic fragments of fibronectin suggested that the $\mathrm{Ch} 3$ fragment contains the region that binds to neurons, we attempted to determine whether an excess of the Ch 3 fragment in the medium would compete with substrate-attached native fibronectin in binding to neurons and thereby inhibit nerve fiber growth. Indeed, addition of the $\mathrm{Ch} 3$ fragment to medium containing fibronectin-free horse serum did inhibit nerve fiber growth in a concentration-dependent fashion (Fig. 8). Simply culturing neurons in complete horse serum, which contains fibronectin, or adding fibronectin to medium containing fibronectin-free horse serum does not inhibit growth of nerve fibers on HEMA/fibronectin substrates (S. Carbonetto, unpublished observations). In these cases, fibronectin in the medium may bind to fibronectin in the gel via the fibronectin self-association site which is lacking in the $\mathrm{Ch} 3$ fragment (Ehrismann et al., 1981, 1982). Unable to associate with the fibronectin embedded in the substrate, the $\mathrm{Ch} 3$ fragment is apparently able to occupy sites on the neuron's surface and thus interfere with a cell-substrate interaction required for nerve fiber growth.

Modulation of nerve fiber growt h by GAGs. As described above, HEMA/GAG substrates were ineffective at supporting nerve fiber growth to an extent that made them

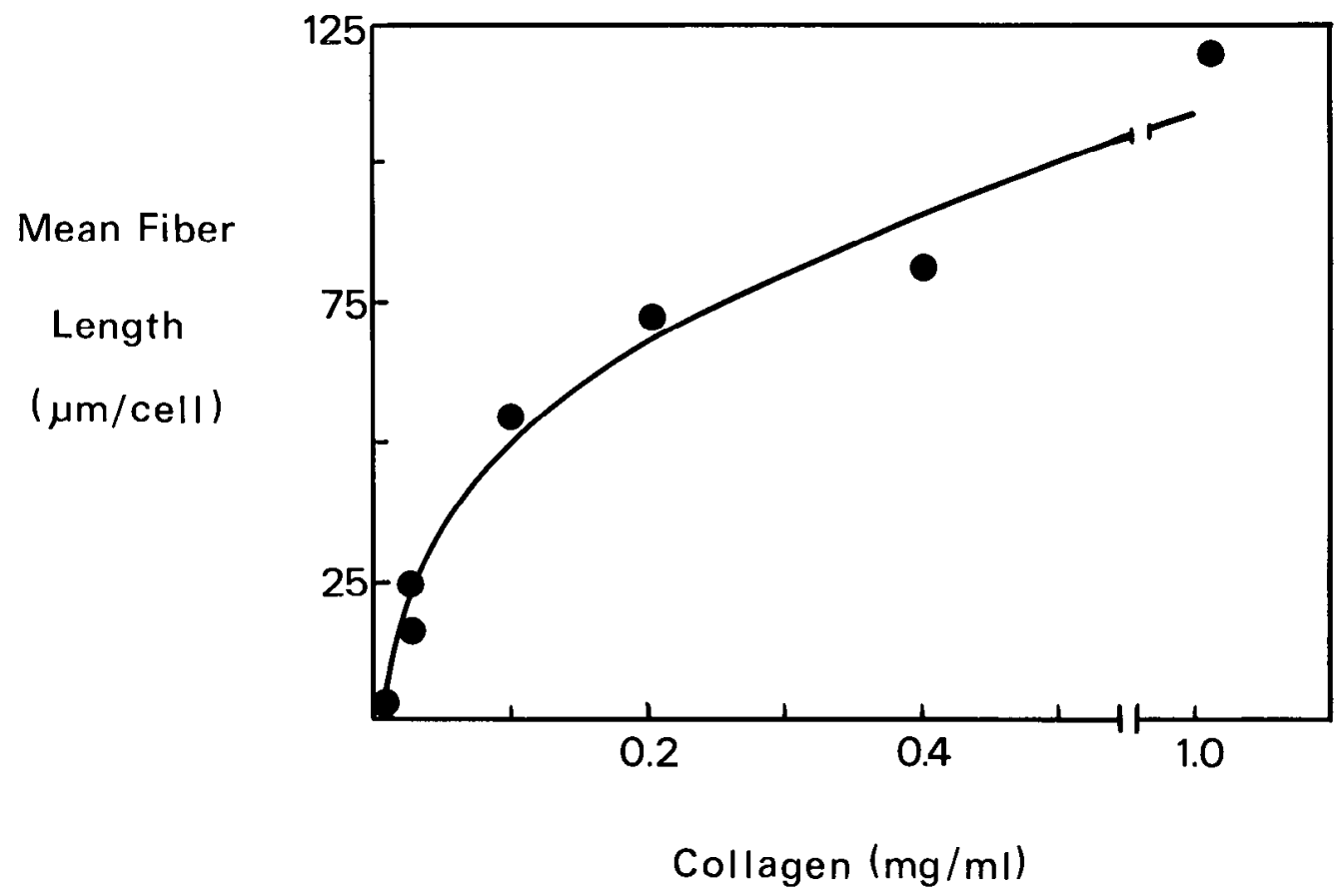

Figure 6. Growth of nerve fibers on HEMA/collagen substrates. DRG cells were cultured overnight on HEMA gel substrates containing a relatively crude preparation of collagen (Sigma, type V). The cultures were fixed with paraformaldehyde and the nerve fiber lengths were determined with an eyepiece micrometer. Data are expressed as the mean nerve fiber length per neuron. The standard error is smaller than the solid circles. 


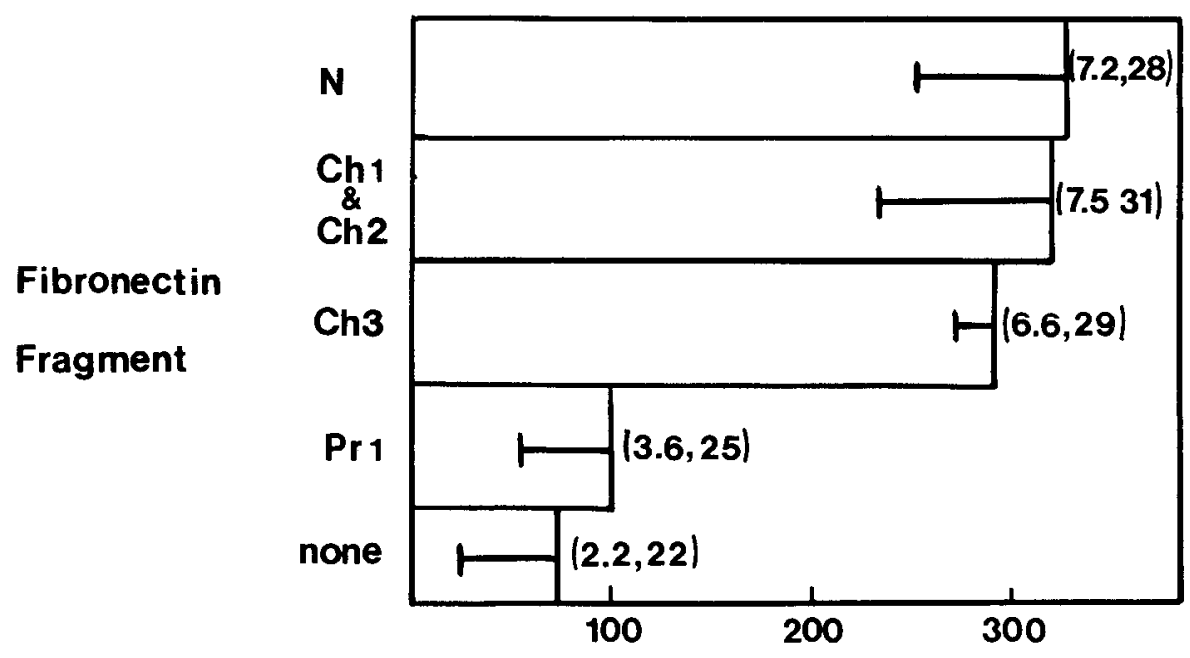

Nerve Fiber Length ( $\mu \mathrm{m} / 100 \mathrm{cells}$ )

Figure 7. Nerve fiber growth on HEMA gels containing fragments of fibronectin. The following fibronectin fragments were incorporated into HEMA gels: $\mathrm{Ch} 1, \mathrm{Ch}$ $2, \mathrm{Ch} 3$, and $\operatorname{Pr} 1 ; N$ refers to intact fibronectin. Data are expressed as in Figure 4.

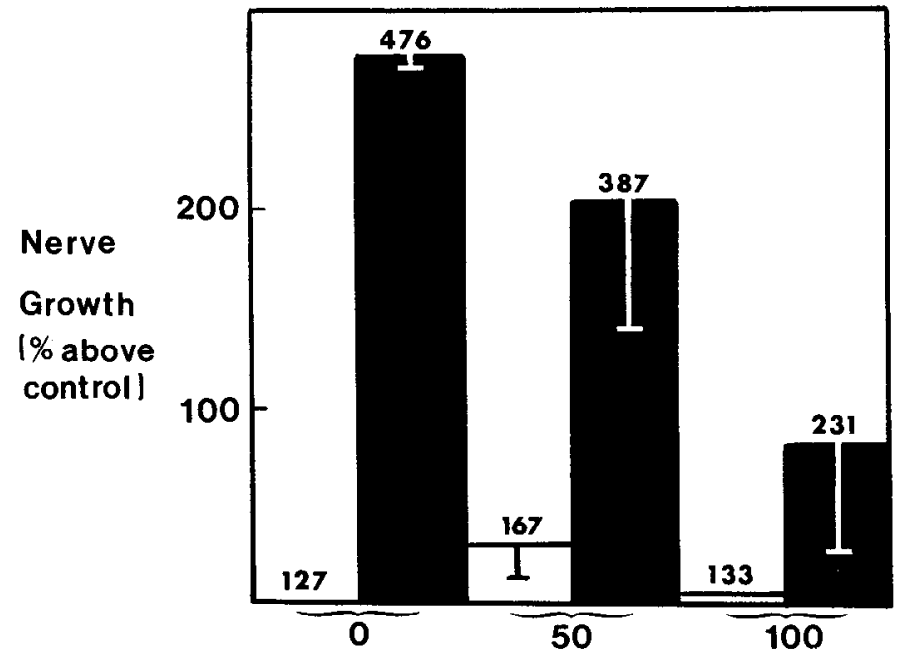

Ch 3 Fragment in Media $\{\mu \mathrm{g} / \mathrm{ml}$ )

Figure 8. Growth of nerve fibers on HEMA/fibronectin gels in medium to which the $\mathrm{Ch} 3$ fragment of fibronectin was added. DRG cells were seeded onto HEMA gels containing fibronectin $(100 \mu \mathrm{g} / \mathrm{ml}$; solid bars) or simple HEMA gels (open bars) in growth medium with fibronectin-depleted horse serum. The cells were allowed to attach for 2 to $4 \mathrm{hr}$, then the medium was replaced with medium to which 0,50 , or $100 \mu \mathrm{g} / \mathrm{ml}$ of $\mathrm{Ch}$ 3 fragment had been added. The cells were maintained in culture for $20 \mathrm{hr}$, after which they were fixed and nerve fiber growth was determined. Nerve fiber growth is expressed as a percentage of growth above that on simple HEMA gels (control). Total nerve fiber growth, expressed as micrometers per 100 cells, is indicated for each group above each bar in the histogram. The standard error is shown.

appear inhibitory. Because of this, we sought to determine whether GAGs could inhibit nerve fiber growth on HFMA/fibronectin substrates. This was tested in two ways: (1) by measuring fiber growth on gels into which heparin was incorporated along with fibronectin, or (2) by measuring growth on HEMA/fibronectin gels treated with heparin prior to seeding of DRG cells on them.

Addition to HEMA gels of heparin along with a concentration of fibronectin which alone would support luxuriant nerve growth resulted in an inhibition of nerve fiber growth on the fibronectin (Table II). At the lowest concentration of heparin added to HEMA/fibronectin gels $(5 \mu \mathrm{g} / \mathrm{ml})$, nerve fiber growth is inhibited by approximately $44 \%$ compared to HEMA/fibronectin gels with no heparin, whereas cell attachment is unaffected (Table II). At higher concentrations of heparin (25 to $300 \mu \mathrm{g} /$ $\mathrm{ml})$ both cell attachment and nerve fiber growth are inhibited. Simply treating HEMA/fibronectin gels with heparin in solution prior to culturing cells also inhibits both neuron attachment and nerve fiber growth (Table II). In this case, as little as $5 \mu \mathrm{g} / \mathrm{ml}$ of heparin in the pretreatment solution reduced attachment and total fiber length by more than half, but had no effect on mean fiber length. Thus, not only are GAGs ineffective as substrates for nerve fiber growth in culture, they can also reduce the efficacy of an otherwise suitable substrate molecule, such as fibronectin, to which they bind.

\section{Discussion}

We have prepared defined culture substrates from HEMA to assess the efficacy of fibronectin, collagen, and GAGs (hyaluronic acid, chondroitin sulfate, and heparin) in supporting nerve fiber growth by cultured neurons. HEMA gels, have several advantages over other methods of preparing culture substrates. First, HEMA substrates are easy to prepare and, unlike other methods (see, e.g., Aplin and Hughes, 1981), require neither chemical modification of the materials to be anchored to the substrate nor chemical modification of the plastic dish or other substrate. Second, the simple HEMA gels used as control substrates are prepared in the same manner 
TABLE II

Effect of heparin on the growth of nerve fibers on HEMA/fibronectin substrates

Three groups of HEMA gels were prepared. The first group contained only heparin ( 0 to $300 \mu \mathrm{g} / \mathrm{ml}$ ) incorporated directly into the gel. The second group contained fibronectin $(100 \mu \mathrm{g} / \mathrm{ml})$ in the gel and were pretreated with heparin before seeding cells $(0$ to $300 \mu \mathrm{g} / \mathrm{ml}$ in Fagle's minimal essential medium). After $1 \mathrm{hr}$, heparin solutions were removed and the gels were washed with $2 \times 1 \mathrm{ml}$ of Eagle's minimal essential medium. The third group contained fibronectin $(100 \mu \mathrm{g} / \mathrm{ml})$ and heparin $(5$ to $300 \mu \mathrm{g} / \mathrm{ml})$ incorporated directly into the gels. DRG cells were cultured overnight, fixed, and scored for fiber growth. Data show the mean values \pm SEM. Nerve fiber length per 100 cells is calculated by multiplying the percentage of neurons with fibers and the mean total nerve fiber length per growing neuron.

\begin{tabular}{|c|c|c|c|c|c|c|}
\hline & $\begin{array}{l}\text { Addition to Gel } \\
\qquad(\mu \mathrm{g} / \mathrm{ml})\end{array}$ & $\begin{array}{l}\text { Heparin Pre- } \\
\text { treatment }(\mu \mathrm{g} / \\
\mathrm{ml})\end{array}$ & $\begin{array}{l}\text { Cell Density } \\
\text { (No./Field) }\end{array}$ & $\begin{array}{l}\% \text { Neurons/Field } \\
\text { Growing Fibers }\end{array}$ & $\begin{array}{c}\text { Mean Total Fiber } \\
\text { Length/Neuron } \\
(\mu \mathrm{m})\end{array}$ & $\begin{array}{l}\text { Fiber Length } / 100 \\
\text { Cells }\end{array}$ \\
\hline Heparin & $\begin{array}{r}5 \\
10 \\
100 \\
300\end{array}$ & & $\begin{aligned} & 26.0 \pm 1.2 \\
& 27.0 \pm 2.3 \\
& 3.7 \pm 1.1 \\
& 0.7 \pm 0.3 \\
& 0\end{aligned}$ & $\begin{array}{c}5.0 \pm 0.8 \\
3.0 \pm 0.9 \\
0 \\
0 \\
0\end{array}$ & $\begin{array}{c}36 \pm 2.4 \\
28 \pm 2.3 \\
0 \\
0 \\
0\end{array}$ & $\begin{array}{r}180 \\
84\end{array}$ \\
\hline Fibronectin & $\begin{array}{l}100 \\
100 \\
100 \\
100 \\
100 \\
100\end{array}$ & $\begin{array}{r}5 \\
10 \\
25 \\
100 \\
300\end{array}$ & $\begin{array}{r}24.0 \pm 1.1 \\
10.0 \pm 1.5 \\
8.6 \pm 1.3 \\
4.0 \pm 0.6 \\
5.4 \pm 0.4 \\
3.1 \pm 0.9\end{array}$ & $\begin{array}{c}13.0 \pm 1.7 \\
6.0 \pm 2.4 \\
1.5 \pm 1.0 \\
0 \\
1.7 \pm 1.7 \\
0\end{array}$ & $\begin{array}{c}64 \pm 4.7 \\
61 \pm 8.4 \\
53 \pm 9.4 \\
0 \\
23 \pm 1.2 \\
0\end{array}$ & $\begin{array}{r}832 \\
366 \\
80 \\
\\
39\end{array}$ \\
\hline $\begin{array}{l}\text { Fibronectin \& } \\
\text { Heparin }\end{array}$ & $\begin{array}{r}(100 \mu \mathrm{g} / \mathrm{ml}) \\
(5 \mu \mathrm{g} / \mathrm{ml})\end{array}$ & & $24.0 \pm 1.1$ & $8.7 \pm 1.3$ & $54 \pm 5.0$ & 470 \\
\hline $\begin{array}{l}\text { Fibronectin \& } \\
\text { Heparin }\end{array}$ & $\begin{array}{r}(100 \mu \mathrm{g} / \mathrm{ml}) \\
(10 \mu \mathrm{g} / \mathrm{ml})\end{array}$ & & $22.0 \pm 1.3$ & $5.1 \pm 1.5$ & $47 \pm 5.3$ & 240 \\
\hline $\begin{array}{l}\text { Fibronectin \& } \\
\text { Heparin }\end{array}$ & $\begin{array}{r}(100 \mu \mathrm{g} / \mathrm{ml}) \\
\quad(25 \mu \mathrm{g} / \mathrm{ml})\end{array}$ & & $16.0 \pm 1.1$ & $4.8 \pm 1.5$ & $49 \pm 4.5$ & 235 \\
\hline $\begin{array}{l}\text { Fibronectin \& } \\
\text { Heparin }\end{array}$ & $\begin{array}{l}(100 \mu \mathrm{g} / \mathrm{ml}) \\
(100 \mu \mathrm{g} / \mathrm{ml})\end{array}$ & & 0 & 0 & 0 & \\
\hline $\begin{array}{l}\text { Fibronectin \& } \\
\text { Heparin }\end{array}$ & $\begin{array}{l}(100 \mu \mathrm{g} / \mathrm{ml}) \\
(300 \mu \mathrm{g} / \mathrm{ml})\end{array}$ & & 0 & 0 & 0 & \\
\hline
\end{tabular}

as modified HEMA gels. Third, a wide variety of molecules, including simple sugars that are otherwise difficult to immobilize as substrates, can be stably incorporated within HEMA gels. Finally, HEMA gels are highly biocompatible and can be fashioned in a variety of shapes (S. Carbonetto and D. Stelzner, unpublished observations); this suggests to us that suitably modified HEMA substrates may be useful as implants in rejoining severed peripheral nerves.

Although the HEMA gels can be used to produce defined substrates, once in culture they may be modified by the medium and/or by the cells or their products. The substrate upon which neurons grow may therefore be much more complex than it was originally. For HEMA/ fibronectin gels several observations suggest that nerve fiber growth depends upon direct interaction with fibronectin and that the source of the fibronectin is most likely that originally added to the gel. First, neurons grow nerve fibers equally well in medium containing fibronectin-free horse serum or complete horse serum. Second, antiserum to fibronectin inhibits nerve fiber growth on HEMA/fibronectin gels when it is added to the medium or when the HEMA/fibronectin gels are treated with the antiserum (Carbonetto et al., 1982). Third, fragments of fibronectin which contain the cell attachment site are effective in supporting nerve fiber growth. Fourth, the addition to the culture medium of the $\mathrm{Ch} 3$ fibronectin fragment, which encompasses the cell attachment site, interferes with the growth of nerve fibers on HEMA/ fibronectin gels. Finally, DRG neurons in culture are notably lacking in surface-associated fibronectin when examined by immunocytochemical techniques (S. Carbonetto, unpublished observations), making non-neuronal cells the most likely cellular source of any fibronectin which could modify the HEMA/fibronectin gels. Yet the non-neuronal cells can be almost completely removed from cultures of DRG cells with no effect on the growth of nerve fibers on HEMA/fibronectin gels (Carbonetto et al., 1982), suggesting that cell-derived fibronectin is not essential for nerve fiber growth. HEMA gels containing connective tissue collagens (types I and III) or collagen derived from basement membrane (type IV) support nerve fiber growth comparable to that on HEMA/fibronectin, even when cells are cultured in medium containing fibronectin-depleted horse serum. It is not known whether neurons attach directly to collagen or whether fibroblast-derived fibronectin bound to the collagen mediates the attachment.

Our studies extend those of Akers et al. (1981), who have shown that fibronectin-coated plastic culture dishes support outgrowth of processes from aggregates of embryonic chick retinal cells. Because individual cells in their aggregates could not be visualized, it is possible that some of the processes were extended by glia (Hatten and Liem, 1981) or that the primary effect of the substrate-bound fibronectin was on the glia, as for example by increasing production of agents which stimulated fiber growth. In our cultures of dissociated DRG cells, neurons can be reliably identified by their spherical somata and long nerve processes. These cells are excitable electrically (S. Carbonetto, unpublished observations) and bind the neurotrophic factor, NGF (Carbonetto and Stach, 1982). 
There is substantial support from our work with dispersed DRG cells and that of Akers et al. (1981) on retinal cell aggregates that neurons from different regions of the embryonic nervous system extend processes on fibronectin. Our data suggest further that this direct interaction with fibronectin involves a limited region of the molecule and that it can be inhibited by GAGs.

The inhibitory effect of GAGs on nerve fiber growth in culture is striking. When incorporated into HEMA gels, GAGS are found to be poor substrates for cell attachment as well as fiber growth. GAGs also greatly reduce the efficacy of HEMA/fibronectin gels in supporting nerve fiber growth. Fibronectin has a specific site at which it binds hyaluronic acid $\left(\mathrm{K}_{d}=10^{-7} \mathrm{M}\right)$ and at least two sites for heparin $\left(\mathrm{K}_{d}=10^{-8}\right.$ and $10^{-9} \mathrm{M}$; reviewed in Yamada et al., 1980; Akiyama et al., 1981). Estimating a molecular weight of about 15,000 for the commercial heparin used in our studies (Lasker and Stivala, 1966; S. Carbonetto, unpublished data), the inhibition of nerve fiber growth on HEMA/fibronectin substrates is evident at about $10^{-7} \mathrm{M}(5 \mu \mathrm{g} / \mathrm{ml})$ and is in good agreement with the $\mathrm{K}_{d}$ for heparin binding to fibronectin. There is considerable evidence that binding of heparin alters fibronectin's conformation and its biological activities (Jilek and Hörmann, 1979; Bray et al., 1981; Hayashi and Yamada, 1982). The effect of low concentrations of heparin in inhibiting nerve fiber growth but not cell attachment on HEMA/fibronectin (Table II) may result from such an interaction between heparin and fibronectin. The effects of higher concentrations of heparin in preventing attachment of cells to simple HEMA substrates as well as to HEMA/fibronectin need not involve this sort of specific intermolecular interaction. At these higher concentrations, GAGs adsorbed to the HEMA and/or to cells may impart a negative charge that prevents cell attachment and nerve fiber growth.

Our studies with defined substrates raise questions concerning the role of GAGs in the nervous system during neuronal differentiation and regeneration. Neuroblasts and nerve processes must be able to form adhesions with other cells or with the substrate in order to migrate. In light of present evidence we would expect that this requirement could be met by fibronectin present in extracellular matrices (Newgreen and Thiery, 1980; Greenberg et al., 1981). The role of GAGs in adhesion and cell motility is unclear. GAGs have been reported to inhibit (Schubert and LaCorbiere, 1980), have no effect (Klebe and Mock, 1982), or stimulate (Laterra et al., 1980) attachment of cells to substrates or other cells, depending on the cell type, their differentiation state, the species and molecular weight of the GAGs, and the substrate or cell to which the adhesion occurs (Klebe and Mock, 1982). Culp et al. (1980) have suggested that hyaluronic acid and chondroitins facilitate the turnover of adhesion sites. Local release of these GAGs by growth cones might then facilitate nerve fiber growth by helping to break adhesions made by the advancing growth cone.

\section{References}

Akers, R. M., D. F. Mosher, and J. E. Lilien (1981) Promotion of retinal neurite outgrowth by substrate-bound fibronectin. Dev. Biol. 96: 179-188.
Akiyama, S. K., K. M. Yamada, and M. Hayashi (1981) The structure of fibronectin and its role in cellular adhesion. J. Supramol. Struct. Cell. Biochem. 16: 345-358.

Aplin, J. D., and R. C. Hughes (1981) Protein-derivatised glass coverslips for the study of cell-to-substratum adhesion. Anal. Biochem. 113: 144-148.

Bondareff, W. (1967) An intercellular substance in rat cerebral cortex: Submicroscopic distribution of ruthenium red. Anat. Rec. 157: 527-536.

Bray, B. A., I. Mandl, and G. M. Turino (1981) Heparin facilitates the extraction of tissue fibronectin. Science 214 : 793-794.

Brock, S. D. (1973) Aspects of three types of hydrogels for biomedical applications. J. Biomed. Mater. Res. 7: 793-794.

Bunge, M. B., A. K. Williams, P. M. Wood, J. Vitto, and J. J. Jeffrey (1980) Comparison of nerve cell and nerve cell plus Schwann cell cultures with particular emphasis on basal lamina and collagen formation. J. Cell Biol. 84: 184-202.

Bunge, R. P., M. B. Bunge, D. T. Carey, C. J. Cornbrooks, D. Higgins, M. I. Johnson, D. C. Kleinschmidt, P. M. Wood, L. Iacovitti, and F. Moya (1982) Functional expression in primary nerve tissue cultures maintained in defined medium. In Growth of Cells in Hormonally Defined Media, G. H. Sato, A. B. Parclee, and D. A. Sirbaskv, eds., pp. 1017-1032, Cold Spring Harbor Laboratory, Cold Spring Harbor, NY.

Carbonetto, S., and R. W. Stach (1982) Localization of nerve growth factor to neurons growing nerve fibers in culture. Dev. Brain Res. 3: 463-473.

Carbonetto, S. T., M. M. Gruver, and D. C. Turner (1982) Nerve fiber growth on defined hydrogel substrates. Science 216: 897-899.

Castejón, M. V. (1970) Histochemical demonstration of sulphated mucopolysaccharides at the surface coat of nerve cells in the mouse nervous system. Acta Histochem. 38: 55-64.

Chiquet, M., E. C. Puri, and D. C. Turner (1979) Fibronectin mediates attachment of myoblasts to a gelatin-coated substratum. J. Biol. Chem. 254: 5475-5482.

Chiquet, M., H. M. Eppenberger, and D. C. Turner (1981) Muscle morphogenesis: Evidence for an organizing function of exogenous fibronectin. Dev. Biol. 88: 220-235.

Civerchia-Perez, L., B. Faris, G. LaPointe, J. Beldekas, H. Leibowitz, and C. Franzblau (1980) Use of collagen-hydroxyethylmethacrylate hydrogels for cell growth. Proc. Natl. Acad. Sci. U. S. A. 72: 2064-2068.

Culp, L. A., R. Ansbacher, and C. Domen (1980) Adhesion sites of neural tumor cells: Biochemical composition. Biochemistry 19: 5899-5907.

Ehrismann, R., M. Chiquet, and D. C. Turner (1981) Mode of action of fibronectin in promoting myoblast attachment. J. Biol. Chem. 256: 4056-4062.

Ehrismann, R., D. E. Roth, H. M. Eppenberger, and D. C. Turner (1982) Arrangement of attachment-promoting, selfassociation, and heparin-binding sites in horse serum fibronectin. J. Biol. Chem. 257: 7381-7387.

Gallagher, J. T., I. N. Hampson, and S. Kumar (1980) Production of sulfated glycosaminoglycans by human neuroblastoma cell cultures. In Advances in Neuroblastoma Research, A. E. Evans, ed., pp. 183-186, Raven Press, New York.

Greenberg, J. H., S. Seppä, H. Seppä, and T. Hewitt (1981) Role of collagen and fibronectin in neural crest cell adhesion and migration. Dev. Biol. 87: 239-266.

Greene, L. A., and E. M. Shooter (1980) The nerve growth factor: Biochemistry, synthesis and mechanism of action. Annu. Rev. Neurosci. 3: 353-402.

Greene, L. A., and A. S. Tischler (1976) Establishment of a noradrenergic clonal line of rat adrenal pheochromocytoma cells which respond to nerve growth factor. Proc. Natl. Acad. Sci. U. S. A. 73: 2424-2428.

Grinnell, F. (1978) Cellular adhesiveness and extracellular sub- 
strata. Int. Rev. Cytol. 53: 65-144.

Hatlen, M. E., and R. K. H. Liem (1981) Astroglial cells provide a template for the positioning of developing cerebellar neurons in vitro. J. Cell Biol. 90:622-630.

Hatten, M. E., M. B. Furie, and D. B. Rifkin (1982) Binding of developing mouse cerebellar cells to fibronectin: A possible mechanism for the formation of the external granular layer. J. Neurosci. 2: 1195-1206.

Hayashi, M., and K. M. Yamada (1982) Divalent cation modification of fibronectin binding to heparin and to DNA. J. Biol. Chem. 257: 5263-5267.

Jilek, F., and H. Hörmann (1979) Fibronectin (cold-insoluble globulin). VI. Influence of heparin and hyaluronic acid on the binding of native collagen. Hoppe-Seylers Z. Physiol. Chem. 360: 597-603.

Kavinsky, C. J., and B. B. Garber (1979) Fibronectin associated with the glial component of embryonic brain cell cultures. J. Supramol. Struct. 11: 269-281.

Klebe, R. J., and P. J. Mock (1982) Effect of glycosaminoglycans on fibronectin-mediated cell attachment. J. Cell. Physiol. 112: 5-9.

Laemmli, U. K. (1970) Cleavage of structural protcins during the assembly of the head of bacteriophage T4. Nature 227: 680-685.

Lasker, S. E., and S. S. Stivala (1966) Physicochemical studies of fractionated bovine heparin. Arch. Biochem. Biophys. 115: $360-372$.

Laterra, J., R. Ansbacher, and L. A. Culp (1980) Glycosaminoglycans that bind cold-insoluble globulin in cell-substratum adhesion sites of murine fibroblasts. Proc. Natl. Acad. Sci. U. S. A. 77: 6662-6666.

I.udueña, M. A. (1973) Nerve cell differentiation in vitro. Dev. Biol. 38: 268-284.

Margolis, R. V., and R. K. Margolis (1979) Complex Carbohydrates of Nervous Tissue, Plenum Press, New York.

Marshall, L. M., J. R. Sanes, and U. J. McMahan (1977) Reinnervation of original synaptic sites on muscle fiber basement membrane after disruption of the muscle cells. Proc. Natl. Acad. Sci. U. S. A. 74: 3073-3077.

McMahan, U. J., J. R. Sanes, and L. M. Marshall (1978)
Cholinesterase is associated with the basal lamina at the neuromuscular junction. Nature (Lond.) 271: 172-174.

Migliaresi, C., L. Nicodemo, L. Nicolais, and P. Passerini (1981) Physical characterization of microporous poly-2-hydroxyethylmethacrylate gels. J. Biomed. Mater. Res. 15: 307-317.

Newgreen, D., and J. -P. Thiery (1980) Fibronectin in early avian embryos: Synthesis and distribution along migration pathways of neural crest cells. Cell Tissue Res. 211: 269-291.

Peters, A., S. Palay, and H. Webster (1976) The Fine Structure of the Nervous System. The Neurons and Supporting Cells, W. B. Saunders Co., Philadelphia.

Richardson, P. M., V. M. McGuinness, and A. J. Aguayo (1980) Axons from $\mathrm{CNS}$ neurons regenerate into PNS grafts. Nature 284: $264-265$.

Sanes, J. R. (1982) Laminin, fibronectin and collagen in synaptic and extrasynaptic portions of muscle fiber basement membrane. J. Cell Biol. 93: 442-451.

Sanes, J. R., L. M. Marshall, and U. J. McMahan (1978) Reinnervation of muscle fiber basal lamina after removal of muscle fibers. J. Cell Biol. 78: 176-198.

Schachner, M., G. Schoonmaker, and R. O. Hynes (1978) Cellular and subcellular localization of LETS protein in the nervous system. Brain Res. 158: 149-158.

Schubert, D., and M. LaCorbiere (1980) A role of secreted glycosaminoglycans in cell-substratum adhesion. J. Biol. Chem. 255: 11564-11569.

Toole, B. P. (1976) Morphogenetic role of glycosaminoglycans (acid mucopolysaccharides) in brain and other tissues. In Neuronal Recognition, S. H. Barondes, ed., pp. 275-329, Plenum Publishing Corp., New York.

Turley, E. A., and S. Roth (1979) Spontaneous glycosylation of glycosaminoglycan substrates by adherent fibroblasts. Cell 17: $109-115$.

Varon, S. S., and R. P. Bunge (1978) Trophic mechanisms in the peripheral nervous system. Annu. Rev. Neurosci. 1: 327362.

Yamada, K. M., D. W. Kennedy, K. Kimata, and R. M. Pratt (1980) Characterization of fibronectin interactions with glycosaminoglycans and identification of active proteolytic fragments. J. Biol. Chem. 255: 6055-6063. 